\title{
Peritonsillar Hematoma Mimicking Peritonsillar Abscess
}

\author{
Mert Cemal Gokgoz ${ }^{1}$, Murat Binar ${ }^{1}$, Hamdi Tasli ${ }^{1}$, Fatih Arslan ${ }^{2 *}$ and Umit Aydin ${ }^{1}$ \\ ${ }^{1}$ Department of Otolaryngology, Head and Neck Surgery, Gulhane Medical Faculty, Turkey \\ ${ }^{2}$ Department of Otolaryngology, Head and Neck Surgery, Beytepe Murat Erdi Eker State Hospital, Turkey
}

Received: 制: September 20, 2018; Published: 些 October 04, 2018

*Corresponding author: Fatih Arslan, Beytepe Murat Erdi Eker State Hospital, Department of Otolaryngology, Head and Neck Surgery, Ankara, Turkey

\begin{abstract}
Oral mucosal hematomas are very rare, and important for respiratory, speech, and swallowing functions. A thirty-four-year-old male patient, who has been suffering from sudden onset sense of swelling and mild pain in his throat. A mild bulging on the left peritonsillar region with echimotic appearance was extending from left side to the medial of right soft palate and the uvula. Computed tomography revealed a haemorrhagic exudative content, approximately $3 * 2.5 * 3 \mathrm{~cm}$ in size. After infiltration anaesthesia, fine needle aspiration was performed. $3 \mathrm{ml}$ pure haemorrhagic material was obtained, and followingly haematoma was completely drained by the incision on the peritonsillar region. In peritonsillar region pathologies, hematoma should be kept in mind for the differential diagnosis of peritonsillar abscess.
\end{abstract}

\section{Introduction}

Hematoma is a collection of blood outside from the vessels under the skin and in the tissue cavities and is often associated with traumatic causes such as bump, fall, injury or surgery. It can occur more easily due to hematologic disease and anticoagulant drug usage. Oral mucosal hematomas are very rare, and important for respiratory, speech, and swallowing functions [1]. Herein, we aimed to present a case of hematoma originating from an uncommon location.

\section{Case Report}

A thirty-four-year-old male patient, who has been suffering from sudden onset sense of swelling and mild pain in his throat, admitted to our clinic. The patient had normal vital signs and normal palpation of the neck. He had a mild odynophagia and minimal trismus (Figure 1). A mild bulging on the left peritonsillar region with echimotic appearance was extending from left side to the medial of right soft palate and the uvula (Figure 1). All laboratory findings were normal. No history of medication, including anticoagulants, was recorded. Contrast-enhanced computed tomography (CT) revealed a haemorrhagic exudative content, approximately $3 * 2.5 * 3 \mathrm{~cm}$ in size, narrowing the oropharyngeal airway, and extending to the border of left parotid gland from peritonsillar region. There was no marked peripheral contrastenhancement around the collection (Figure 2). Patient's history, clinical signs, imaging and other findings were highly suggestive of haematoma. After infiltration anaesthesia on peritonsillar mucosa, fine needle aspiration was performed. $3 \mathrm{ml}$ pure haemorrhagic material was obtained, and followingly haematoma was completely drained by the incision on the peritonsillar region. The patient was hospitalized, and anti biotherapy was administered due to surgical intervention. Written informed consent was also obtained from the patient who participated in this paper.

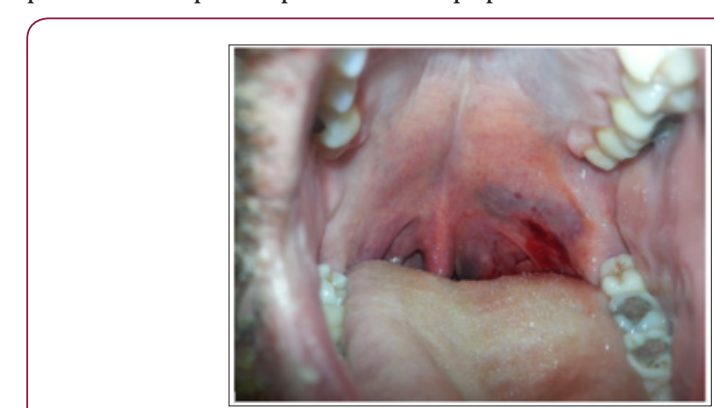

Figure 1: Mild bulging on the left peritonsillar region with echimotic appearance was extending from left side to the right soft palate and through the uvula and no trismus.

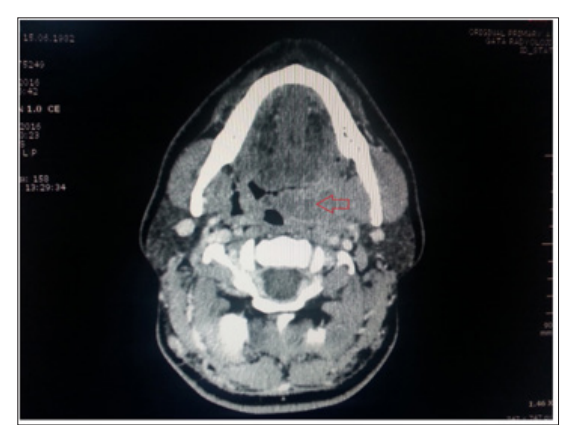

Figure 2: Axial CT image showing left peritonsillar haemorrhagic collection (HU score:67). 


\section{Discussion}

In this case, minimal trismus, absence of acute tonsillitis, and absence of hot potato voice were clinical findings that differ from peritonsillar abscess. In our patient, the contrast-enhanced CT findings suggested the hematoma developing in this region. In the English literature, only one patient had peritonsillar hematoma, who had a warfarin usage history [1]. Aspiration and biopsy should be avoided in the presence of internal carotid artery pseudoaneurysm and angiofibromas with peritonsillar zone extension. In the presence of these pathologies, aspiration may lead to abundant bleeding and neurological complications. In this patient, needle aspiration decision was taken after CT evaluation and it was recognized that there was no vascular connection of hematoma zone [2]. The treatment of hematoma depends on the localization, size, and signs of patients. The treatment is initially surgical drainage and bleeding control. Hematoma resolves rapidly after drainage. In general, antibiotherapy is started prophylactically due to surgical intervention. All patients with peritonsillar hematoma must be observed closely to control airway and re-collection of blood. Our patient's treatment was drainage and antibiotherapy. Complete resolution of symptoms was observed at the third day, therefore additional treatment was not necessary.

\section{References}

1. N Fergie, A Murray, RA Kell (1997) Peritonsillar Haematoma. J Laryngol Otol 111(3): 266-268.

2. Mordekar SR1, Bradley PJ, Whitehouse WP, Goddard AJ (2005) Occult carotid pseudoaneurysm following streptococcal throat infection. J Paediatr Child Health 41(12): 682-684.
ISSN: 2574-1241

DOI: 10.26717/BJSTR.2018.09.001823

Fatih Arslan. Biomed J Sci \& Tech Res

(C) This work is licensed under Creative

Submission Link: https://biomedres.us/submit-manuscript.php

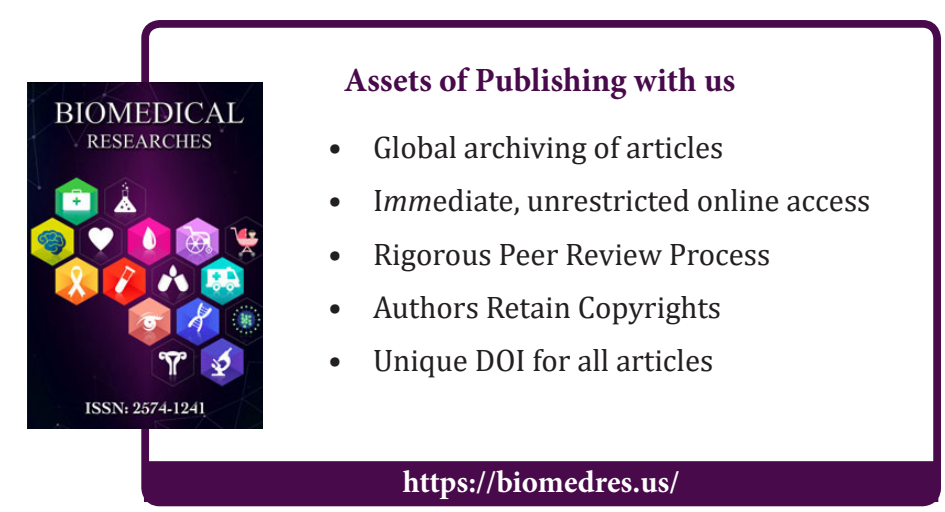

